\title{
Population dynamics of house mice in Queensland grain- growing areas
}

\author{
Anthony Pople ${ }^{\mathrm{A}, \mathrm{E}}$, Joe Scanlan ${ }^{\mathrm{B}}$, Peter Cremasco ${ }^{\mathrm{B}, \mathrm{C}}$ and Julianne Farrell ${ }^{\mathrm{B}, \mathrm{D}}$ \\ A Invasive Plant and Animal Science, Biosecurity Queensland, Department of Agriculture, \\ Fisheries and Forestry, Queensland, Ecosciences Precinct, GPO Box 267, Brisbane, Qld 4001, Australia. \\ ${ }^{B}$ Robert Wicks Pest Animal Research Centre, Biosecurity Queensland, Department of Agriculture, \\ Fisheries and Forestry, 203 Tor Street, Toowoomba, Qld 4350, Australia. \\ CInvasive Species Branch, Department of Primary Industries, Parks, Water and Environment, \\ PO Box 46, Kings Meadows, Tas. 7249, Australia. \\ D11/301 Bridge Street, Toowoomba, Qld 4350, Australia. \\ ${ }^{\mathrm{E} C}$ Corresponding author. Email: tony.pople@daff.qld.gov.au
}

\begin{abstract}
Context. Irregular plagues of house mice cause high production losses in grain crops in Australia. If plagues can be forecast through broad-scale monitoring or model-based prediction, then mice can be proactively controlled by poison baiting.

Aims. To predict mouse plagues in grain crops in Queensland and assess the value of broad-scale monitoring.

Methods. Regular trapping of mice at the same sites on the Darling Downs in southern Queensland has been undertaken since 1974. This provides an index of abundance over time that can be related to rainfall, crop yield, winter temperature and past mouse abundance. Other sites have been trapped over a shorter time period elsewhere on the Darling Downs and in central Queensland, allowing a comparison of mouse population dynamics and cross-validation of models predicting mouse abundance.

Key results. On the regularly trapped 32-km transect on the Darling Downs, damaging mouse densities occur in $50 \%$ of years and a plague in $25 \%$ of years, with no detectable increase in mean monthly mouse abundance over the past 35 years. High mouse abundance on this transect is not consistently matched by high abundance in the broader area. Annual maximum mouse abundance in autumn-winter can be predicted $\left(R^{2}=57 \%\right)$ from spring mouse abundance and autumn-winter rainfall in the previous year. In central Queensland, mouse dynamics contrast with those on the Darling Downs and lack the distinct annual cycle, with peak abundance occurring in any month outside early spring. On average, damaging mouse densities occur in 1 in 3 years and a plague occurs in 1 in 7 years. The dynamics of mouse populations on two transects $\sim 70 \mathrm{~km}$ apart were rarely synchronous. Autumn-winter rainfall can indicate mouse abundance in some seasons $\left(R^{2}=\sim 52 \%\right)$.

Conclusion. Early warning of mouse plague formation in Queensland grain crops from regional models should trigger farm-based monitoring. This can be incorporated with rainfall into a simple model predicting future abundance that will determine any need for mouse control.
\end{abstract}

Implications. A model-based warning of a possible mouse plague can highlight the need for local monitoring of mouse activity, which in turn could trigger poison baiting to prevent further mouse build-up.

Received 11 September 2013, accepted 29 January 2014, published online 27 February 2014

\section{Introduction}

Damaging numbers of house mice (Mus domesticus) occur irregularly in grain crops in south-eastern Australia. These are costly in terms of lost production and growers attempt to prevent or mitigate these losses through a range of measures, including baiting and habitat modification (Brown et al. 2004). In years when mouse numbers are low, losses are negligible and control is not warranted. However, when mouse densities are high, farmers generally implement control when they see damage. This reactive response does not necessarily prevent substantial losses (Davis et al. 2004). If plagues can be predicted with sufficient warning, then preventative or preparatory action can be taken.

Davis et al. (2004) identified that control is warranted if the likelihood of a plague (P) is greater than the cost of pre-emptive control (C) divided by the product of the damage cost (Q) and control effectiveness (z) (i.e. $\mathrm{P}>\mathrm{C} / \mathrm{Qz}$, which was roughly estimated as 0.30 for south-eastern Australia). Even without a forecast, it is still beneficial to control mice if plague frequency is greater than C/Qz. For a predictive model based on rainfall, Davis et al. (2004) determined a rainfall threshold above which it is worth implementing control for mice in south-eastern Australia. 


\section{Relationship between density and damage}

The terms 'plague' or 'outbreak' are loosely defined, but generally refer to substantial crop losses over large areas involving several farms. Singleton et al. (2005) offered a more precise definition by relating damage to mouse density. At densities of $<50$ mice ha $^{-1}$ there were no economic losses. Densities of 50-200 mice ha ${ }^{-1}$ were described as an outbreak and resulted in low losses to cereal crops, and high losses to vegetable crops and stored grain. Densities of $>200$ mice ha $^{-1}$ were considered a plague, with high economic losses on a broad scale. At densities of $>800$ mice ha $^{-1}$, a plague was severe, with losses over thousands rather than hundreds of square kilometres.

Cantrill (1992) suggested that grain growers consider that mice are 'present' in crops at densities of 10 mice per 100 breakback traps and are causing damage (and presumably requiring control) at 20 mice per 100 break-back traps (equivalent to $\sim 100$ mice ha $^{-1}$, J. Caughley, unpubl. data). Brown and Singleton (1999) suggested the threshold density at which farmers consider mice a problem is 200 mice ha $^{-1}$. They further argued that once mice reached this density, it was likely to be too late for cost-effective management.

Kaboodvandpour and Leung (2012) quantified the relationship between mouse density and wheat yield loss by releasing mice into crops at the milky stage of development and enclosed by a mouse-proof fence. They recorded a linear increase in yield loss with increasing mouse density up to 500 mouse ha $^{-1}$, when intraspecific competition is the likely cause for a curvilinear relationship that asymptotes at extremely high mouse densities. These data were then used to suggest density thresholds above which it was economically beneficial to control mice. Likely thresholds, assuming baiting effectiveness of $\sim 40 \%$ and 2001 crop values and baiting costs, were $\sim 90$ mice ha $^{-1}$. Similar relationships were recorded for sorghum crops.

\section{Plague incidence}

On the basis of qualitative data such as newspaper accounts, the frequency of plagues is roughly 1 in 7 years in any particular state (Singleton et al. 2005). However, the frequency is higher on the Darling Downs in Queensland, where plagues have occurred on average every 3 years since 1980, up from an average of once every 10 years before that (Singleton and Brown 1999). Notably, according to the framework of Davis et al. (2004), a frequency of 1 in every 3 years makes annual control worthwhile, even if the chance of a plague is the same from year-to-year. However, on individual farms where decisions on mouse control are made, the plague frequency appears to be less frequent than that reported for the broader region (Donkin and Caughley 1998). The increased plague frequency on the Darling Downs has been attributed to changes in farming practices such as retained stubble providing mice with cover, reduced disturbance from sheep grazing and tillage, and increased intensity and diversity (i.e. variable planting and harvesting times) of cropping leading to a more reliable and higherquality food supply through the year (Singleton and Brown 1999). Caughley (2001) questioned this purported increased frequency of plagues, suggesting it reflected a change in methodology for determining the incidences of plagues rather than a true increase. An increased frequency of plagues (of similar density) would also result in a trend of increased density over time. Changes in farming practices may also have increased the average or maximum density of mice in any one year. However, Caughley (2001) was unable to detect an increase in average density in early winter over 1974-2001 along the central Darling Downs transect (see below). Caughley (2001) suggested that stubble retention and other changes in land management changed only the distribution of mice in the landscape and not their average density.

\section{Plague-prediction models}

Models for predicting mouse plagues in south-eastern Australia have been developed from either long-term qualitative data on the occurrence of plagues from newspaper reports or shorterterm trapping data (see Pech et al. 1999 for a review). Both approaches can yield a probability of a plague occurring using logistic regression. With trapping data, density or rate of increase can be predicted. For southern Australia, recent modelling efforts with qualitative data (1900-2002) identified a combination of winter (May-September) and spring (November) rainfall as the best predictor of a plague (Kenney et al. 2003). Using a large trapping dataset ( $>20$ years) from southern Australia, maximum autumn density was best predicted by the previous year's autumn-spring (April-October) and summer (December) rainfall and spring (September) mouse density (Krebs et al. 2004). For both these analyses, wheat yield was a poorer predictor of mouse abundance than was rainfall, which was surprising as it was expected to be a better proxy for food supply (Mutze et al. 1990; Pech et al. 1999).

In Queensland, Cantrill (1992) described the population dynamics of house mice on the basis of trapping data (1974-1986) from a 32-km transect in the central Darling Downs. In southern Australia, mice remain at low densities, often for many years, outside plague years. In contrast, mouse density along the central Darling Downs transect underwent regular seasonal cycles, with maximum abundance varying along a continuum, rather than distinct plague and nonplague years. Cantrill (1992) argued that mouse numbers rose unvaryingly from a seasonal low in spring at the onset of breeding, to a maximum in late autumn or early winter. Relatively high numbers in spring ( $>1 \%$ trap success) were therefore likely to translate into a plague the following year. The exceptions were years with flooding spring-summer rains that had the potential to suppress the rate of increase, probably through increased juvenile mortality. Spring abundance of mice was negatively correlated with abundance in the preceding winter. The decline in mouse numbers over winter was also exacerbated by low winter temperatures and a lack of favourable habitat following the harvest of summer crops, forcing large dispersal distances (Cantrill 1992; Caughley 2001). Cantrill (1992) developed an expert system model to provide probabilities of density classes of mice in late autumn. Data required for prediction were

- trap success in the previous autumn (May) (long-term prediction),

- trap success in spring (September) (mid-term prediction), and 
- trap success in September and monthly trap success or rainfall for spring-summer (September-December) (shortterm prediction).

Pech et al. (2003) identified the following three demographic factors that are responsible for the development of plagues in mice populations in Australian grain-growing areas:

(1) The population density at the start of the breeding season. This is the result of the overwinter decline from an autumn maximum; these two variables are negatively correlated and this formed the basis of Cantrill's (1992) long-term prediction.

(2) The rate of increase over the breeding season, which, at least in southern Australia, is influenced by winter-spring rainfall, but not starting density (or at least only trivially).

(3) The duration of the breeding season, which is unaffected by the above two factors, but is variable and probably not predictable. Despite breeding, mice on the Darling Downs may not increase because of flood mortality and so the model of Cantrill (1992) relied on trapping or spring-summer rainfall to determine the start of the 'increase phase'.

These factors seem to be independent, indicating that all three need to be estimated so as to accurately predict the occurrence of plagues.

\section{Study objectives}

Trapping has continued along the central Darling Downs transect and other grain-growing areas in Queensland. Using these data, the present paper aims to better describe the dynamics of mouse populations in these areas and refine or develop new models to predict mouse numbers for improved mouse management in crops. The question addressed here is whether damaging mouse numbers can be predicted from simple proxies for food supply (i.e. rainfall, crop yield), weather (i.e. flooding, winter temperature) and past mouse abundance with sufficient accuracy and timeliness to be useful to crop farmers. Past work described above provides candidate parameters. The longer time series also allows a renewed assessment of whether mouse abundance has increased on average in the Darling Downs.

Scanlan and Farrell (2005) used artificial neural networks to model mouse abundance in central Queensland, using data up to 2004. They found that summer and autumn rainfall, coupled with summer mouse abundance, could be used to predict winter mouse abundance. This result was also reassessed with a longer time series.

\section{Methods}

Three statistical approaches were taken to analyse trapping data so as to describe the population dynamics of house mice in Queensland cropping areas. First, time-series analysis was used to understand the autocorrelation structure of the data, describe the seasonal cycles and test for any long-term trend in mouse density. Second, regression models were used to predict mouse density from likely explanatory variables. Finally, exponential rate of increase in mouse abundance was modelled as the response variable in regression models. Cross-validation of regression models was possible in some cases, using independent data.

\section{Study areas and trapping, weather and crop data}

In the central Darling Downs, house mice have been trapped at 47 sites along a $32-\mathrm{km}$ transect between Cecil Plains $\left(27^{\circ} 30^{\prime} \mathrm{S}\right.$, $\left.151^{\circ} 11^{\prime} \mathrm{E}\right)$ and Mount Tyson $\left(27^{\circ} 34^{\prime} \mathrm{S}, 151^{\circ} 34^{\prime} \mathrm{E}\right)$ over 1974-2008 (Fig. 1). At each site, 20 break-back traps were baited with bacon, placed $10 \mathrm{~m}$ apart along a line and left overnight. Trapping data can be expressed as the number caught (less the number of traps that fired but did not capture a mouse) per 100 trap-nights (= 'unadjusted' trap success). Cantrill (1992) used this measure of trap success as a basis for his modelling. The proportion of traps capturing mice $(P)$ can be adjusted to an index of density $(I)$ to account for trap saturation (Caughley 1977) as $I=-\ln (1-P)$ (= 'adjusted' trap success). This was done here, which is consistent with other, more recent models (e.g. Pech et al. 1999; Krebs et al. 2004).

House mice were also trapped intermittently over 1998-2008 along a transect, comprising 20 sites, each with 10 traps, in the northern Darling Downs between Macalister $\left(27^{\circ} 01^{\prime} \mathrm{S}\right.$, $\left.151^{\circ} 04^{\prime} \mathrm{E}\right)$ and Irvingdale $\left(27^{\circ} 11^{\prime} \mathrm{S}, 151^{\circ} 30^{\prime} \mathrm{E}\right)$ and along another transect, comprising 20 sites, each with 10 traps, in the eastern Darling Downs between Black Plains $\left(27^{\circ} 53^{\prime} \mathrm{S}\right.$, $\left.151^{\circ} 47^{\prime} \mathrm{E}\right)$ and Pilton $\left(27^{\circ} 51^{\prime} \mathrm{S}, 152^{\circ} 02^{\prime} \mathrm{E}\right)$ (Fig. 1). In central Queensland, a transect comprising 22 sites, each with 20 traps, was trapped intermittently over 1990-2008 in the Dawson Valley between Moura $\left(24^{\circ} 56^{\prime} \mathrm{S}, 150^{\circ} 04^{\prime} \mathrm{E}\right)$ and Theodore $\left(24^{\circ} 33^{\prime} \mathrm{S}, 149^{\circ} 58^{\prime} \mathrm{E}\right)$ and another transect comprising 24 sites, each with 20 traps, was trapped intermittently over the same period in the Callide Valley between Jambin $\left(24^{\circ} 11^{\prime} \mathrm{S}, 150^{\circ} 22^{\prime} \mathrm{E}\right)$ and Thangool $\left(24^{\circ} 28^{\prime} \mathrm{S}, 150^{\circ} 34^{\prime} \mathrm{E}\right)$ (Fig. 1).

For all study areas, trap-site locations were fixed and represented a variety of habitats used by mice in the district, including cultivated paddocks (regardless of cropping stage), roadside verges and native grasslands. Typically, there were two trap lines (i.e. sites) at each location, one in cultivation, the other in an uncultivated area.

Monthly rainfall over the study period was estimated for each transect as averages of rainfall (Bureau of Meteorology, http://www.bom.gov.au/climate/data/, verified 12 May 2009) from nearby stations, as follows:

central Darling Downs: Cecil Plains Homestead $($ mean $=666 \mathrm{~mm}$, s.d. $=176 \mathrm{~mm})$, Condamine Plains and Mount Irving;

northern Darling Downs: Bundaleer $\quad($ mean $=625 \mathrm{~mm}$, s.d. $=143 \mathrm{~mm}$ ), Wilga Home and Macalister;

eastern Darling Downs: Nobby Tooth Street (mean $=737 \mathrm{~mm}$, s.d. $=161 \mathrm{~mm}$ ) and Clifton Post Office;

Dawson Valley: Moura $($ mean $=677 \mathrm{~mm}$, s.d. $=202 \mathrm{~mm})$ and Theodore; and

Callide Valley: Jambin $($ mean $=689 \mathrm{~mm}$, s.d. $=187 \mathrm{~mm})$, Biloela and Thangool.

To reflect the mildness of winters, the median of the mean and the lowest minimum temperatures for June, July and August were calculated for each year over the study period 


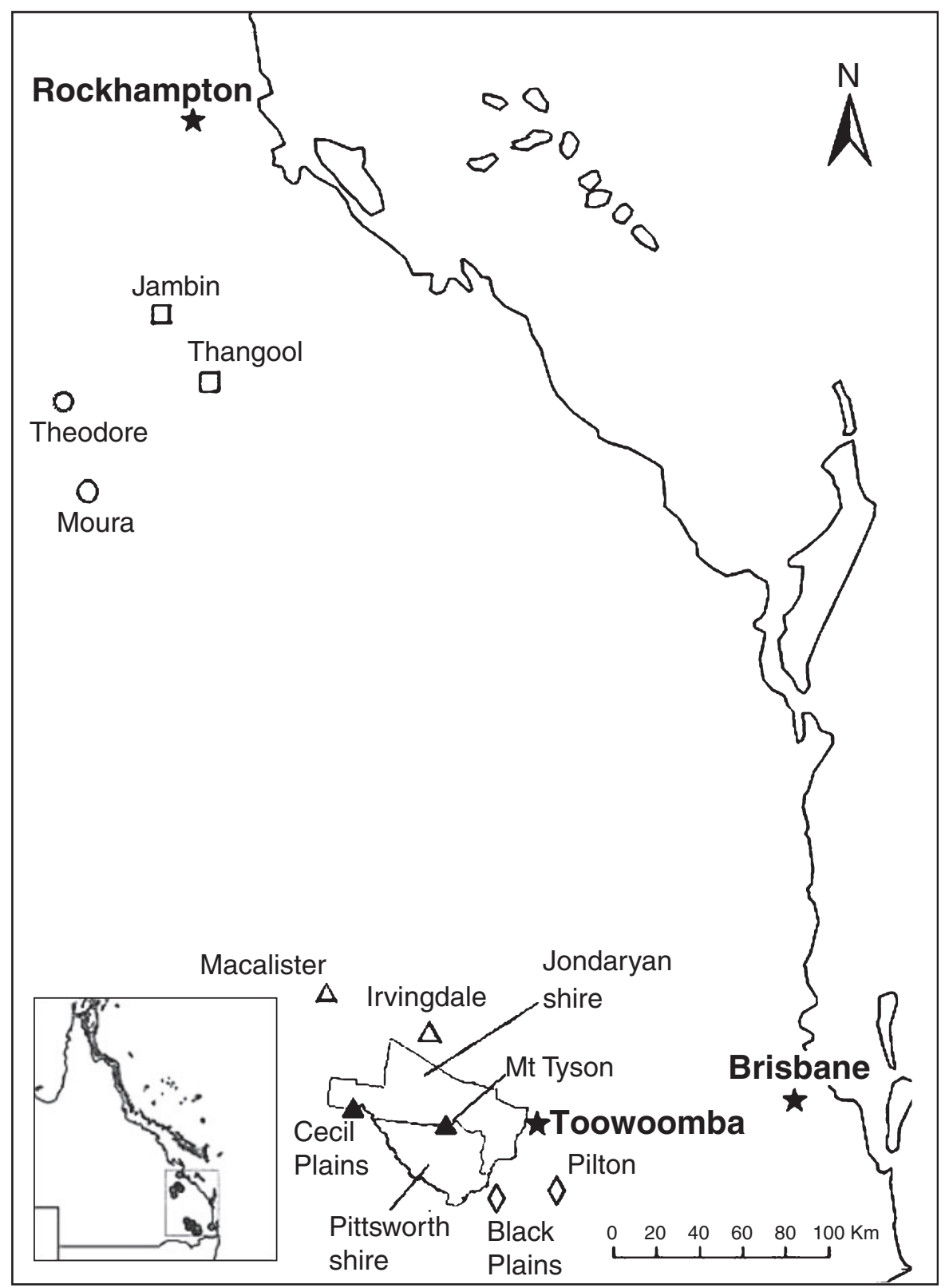

Fig. 1. Location of endpoints of transects of trapping sites for mice in the central Darling Downs (solid triangles), northern Darling Downs (open triangles), eastern Darling Downs (open diamonds), Dawson Valley (open circles) and Callide Valley (open squares). Cereal-crop yield was recorded for the Jodaryan and Pittsworth shires, whose boundaries are also shown.

from Bureau of Meteorology records. The closest weather stations recording temperature to each of the above transects, respectively, were Oakey, Dalby, Toowoomba, Brigalow Research Station and Thangool.

For the central Darling Downs transect, summer and winter cereal-crop yield were calculated from the Australian Bureau of Statistics records. For 1973-2002 and 2005-06, these were available for shires, so transect values were calculated as the average of estimates for Pittsworth and Jondaryan shires (Fig. 1), which the transect spans. For 2002-05 and 2006-09, an estimate was available only for the statistical division of the
Darling Downs. Transect estimates were therefore calculated as a proportion of the Darling Downs estimates, with the proportion determined as (average crop yield for Pittsworth and Jondaryan shires)/(crop yield for Darling Downs statistical division), averaged across the most recent years, 2001-02 and 2005-06.

\section{Time-series analysis}

Autocorrelations and partial autocorrelations for monthly adjusted trap successes along the central Darling Downs 
transect were calculated in R (R Development Core Team 2010). Following Crawley (2007) to test for trend, mixed models predicting adjusted trap success were fitted using maximum likelihood, with and without an index term for the number of months since the start of the time series. Models included terms for seasonal cycles (comprising $\sin (2 \times \pi \times$ time) and $\cos$ $(2 \times \pi \times$ time $)$ terms $)$ and different intercepts for each year. As an alternative, yearly means for adjusted trap success were regressed against an index term for each year (Crawley 2007).

\section{Regression analyses}

For the Darling Downs transects, missing values required the response variable to be the maximum trap success recorded over April-August ('autumn-winter'). Trap success was transformed to natural logarithms to improve linearity. Regression models predicting maximum abundance were fitted in $\mathrm{R}$ using a range of explanatory variables, including the following:

(1) maximum autumn-winter mouse abundance from the previous year,

(2) minimum winter temperature from the previous year,

(3) food supply, either autumn-winter rainfall from the previous year or winter crop yield from the previous year;

(4) spring mouse abundance (usually September, but October in one year); and

(5) spring-summer (September-December) rainfall, as either absolute rainfall or a dummy variable based on the argument of Cantrill (1992) that consecutive months of $>40-\mathrm{mm}$ rainfall during September-December delayed the population increase through nestling mortality.

Two sets of models were fitted, namely, one with and one without spring mouse abundance. With spring abundance available, the forecast is short-term. Mouse abundance and minimum temperature in the previous winter are proxies for spring abundance and provide a longer-term forecast. Interactions and curvilinear terms were also included, but the number of terms was constrained by the number of observations $(n)$. The recommended maximum number of fitted parameters ranges from $n / 6$ (Neter et al. 1996) to $n / 3$ (Crawley 2007). With only $n=32$, not all potential interactions and curvilinear terms could be assessed. The approach was to test for curvilinearity first, followed by a restricted (if necessary) set of interactions (Crawley 2007). Models were simplified by stepwise removal of non-significant $(P>0.05)$ terms from the full model (Crawley 2007).

The slope of the regression of monthly values of $\log _{\mathrm{e}}$ (adjusted \% trap success) over time (spring-autumn, September-May) provides an estimate of the exponential rate of increase. Models with common or separate slopes were compared in an analysis of covariance to test the assertion (Cantrill 1992) that mouse numbers increase at a constant rate among years from spring, unless there is flooding spring-summer rain.

Potential determinants of monthly exponential rate of increase $\left(\ln \left(I_{\mathrm{t}+1} / I_{\mathrm{t}}\right)\right)$ were also assessed through multiple regression. Rates of increase were calculated between consecutive seasons, using average trap success in spring (September), summer (November-January) and autumn
(March-May) and maximum trap success in winter (June-August). Rate of increase was also calculated between the annual maximum (April-August) and the following spring. Winter and annual maxima were used to measure abundance at both the start of the decline phase (usually June-July) and end of the increase phase (about May). Explanatory variables in addition to those above included seasonal rainfall, initial trap success and summer crop yield.

To test the resulting best models against independent data in a different climate on the eastern and northern Darling Downs required rainfall and temperature to be converted to standard deviation units (or $z$-scores). September abundance for these areas was also converted to $z$-scores by using the mean and standard deviation for September abundance on the central Darling Downs transect. Using $z$-scores for all explanatory variables produced standardised parameter estimates that indicate relative importance.

For central Queensland, models developed for the Darling Downs were clearly not going to be applicable as maximum abundance did not necessarily occur over autumn-winter and, more generally, there was no clear seasonal cycle. Therefore, monthly exponential rates of increase were calculated between seasons, using true seasonal calendar months in this case, and related to 6-monthly rainfall at increasing monthly lags, following the approach of Brown and Singleton (1999). Initial abundance was also included as a potential explanatory variable (Pech et al. 1999). This approach of simple linear correlation and regression was used to reassess the models of Scanlan and Farrell (2005) to predict winter mouse abundance.

\section{Results}

\section{Trapping data and time-series analysis}

The time series of unadjusted trap success for each of the five transects is shown in Fig. 2. In discussing these results, years refer to biological years, starting at a low density in spring of the previous calendar year and ending at a maximum in autumn or winter of the following calendar year. For the central Darling Downs, there are regular seasonal peaks of density in late autumn or early winter, as described by Cantrill (1992), with the broadscale plague of 1995 being prominent among them. The time series is incomplete, but of the 32 years that were trapped, 16 (i.e. 50\%) experienced mouse densities greater than the damage threshold of $20 \%$ trap success of Cantrill (1992). In eight of these years (i.e. $25 \%$ ), trap success was greater than $32 \%$, being roughly equivalent to the plague threshold of 200 mice ha $^{-1}$. Years with high trap success were often, but not always, followed by a low-density year. Over 1982-85 and 19992001, there were four and three consecutive years, respectively, of trap success $>20 \%$. There were also notable runs of low maximum trap success over 1990-92 and 200407 . These were dry years, although not remarkably so.

For the northern and eastern Darling Downs, autumn trap success was recorded in only 5 or 6 years, respectively, and exceeded $20 \%$ twice and once, respectively. These peak years coincided with maxima $>20 \%$ over autumn-winter (i.e. April-August) on the central Darling Downs transect. However, the eastern Darling Downs transect recorded autumn-winter maxima in 1999 and 2003 of $<10 \%$ that were 

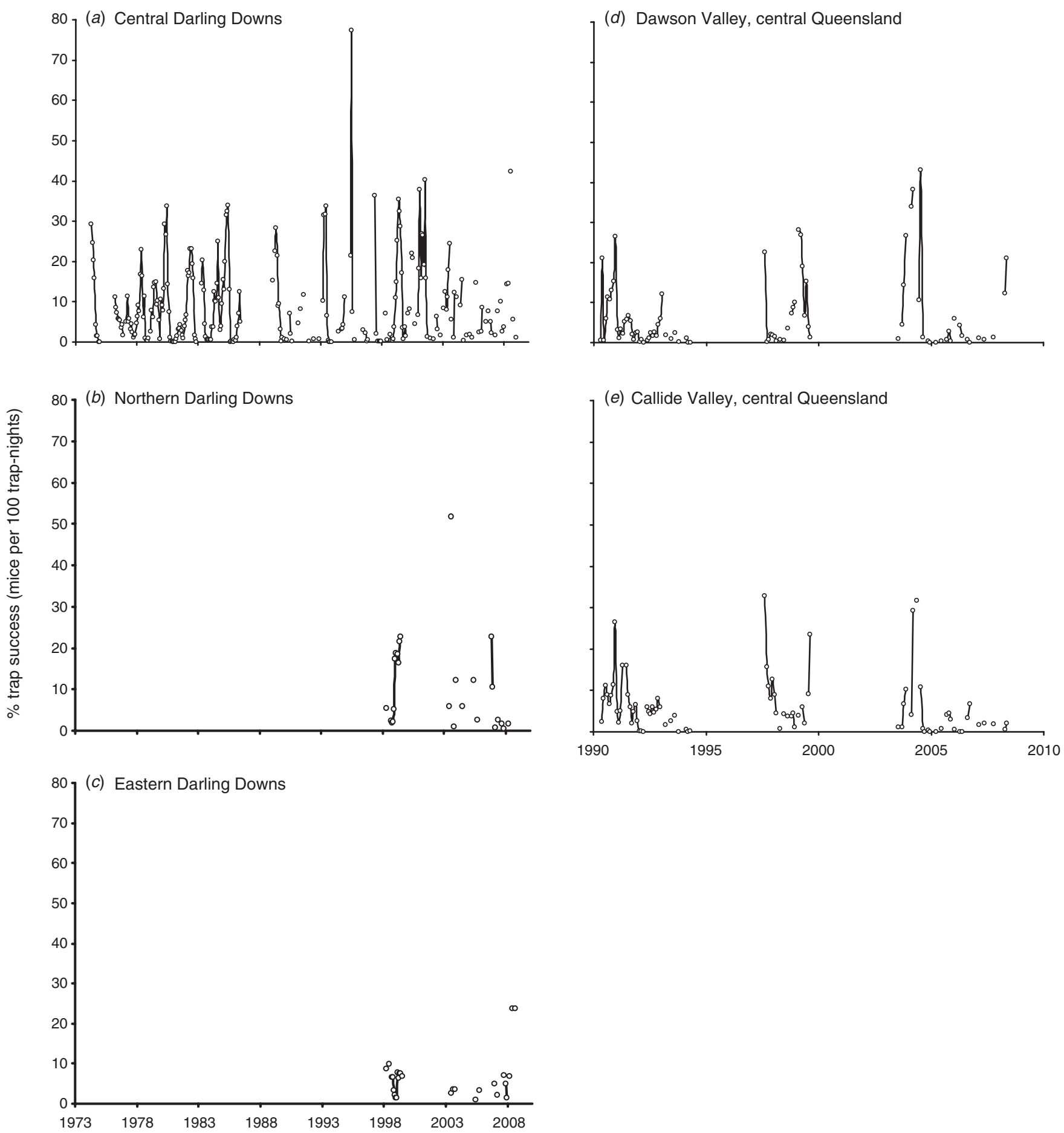

Fig. 2. Monthly unadjusted trap success (mice caught per 100 trap-nights) for four transects in Queensland (Fig. 1). (a) Central Darling Downs; $(b)$ northern Darling Downs; $(c)$ eastern Darling Downs; $(d)$ Dawson Valley, central Queensland; and $(e)$ Callide Valley, central Queensland. Values for consecutive months are connected by lines.

well below the high abundance $(>20 \%)$ recorded on the other two transects. Trap success was $23 \%$ in November 2006 on the northern Darling Downs transect, but mouse abundance subsequently declined following a dry winter-summer. A comparison of maximum autumn-winter trap success on the eastern and northern Darling Downs transects with those on the central Darling Downs transect is shown in Fig. 3. Density was almost always higher on the central Darling Downs and, more importantly, high densities ( $>20 \%$ trap success) recorded there were matched by high densities on the other two transects 
in only two of five cases. However, there was a broad match for low densities, using a cut-off of $10 \%$ trap success.

In central Queensland, mouse populations fluctuate in a manner different from those in the Darling Downs. There is no distinct annual cycle and peak abundance can occur in any month across November-August. Despite their relatively close proximity $(\sim 70 \mathrm{~km})$, the dynamics of mouse populations on the two transects were rarely in concert and high densities ( $>20 \%$ trap success) were matched on the two transects in only 3 of 10 cases (Fig. 4). For the two transects, mice were trapped in 14 of the 19 years of the study period. In the Dawson Valley, monthly trap success exceeded $20 \%$ in 6 years $(43 \%)$ and was $>32 \%$ in 2 years (14\%). In the Callide Valley, trap success was $>20 \%$ in 4 years $(29 \%)$ and $>32 \%$ in 2 years $(14 \%)$. However, sampling was incomplete within years, particularly

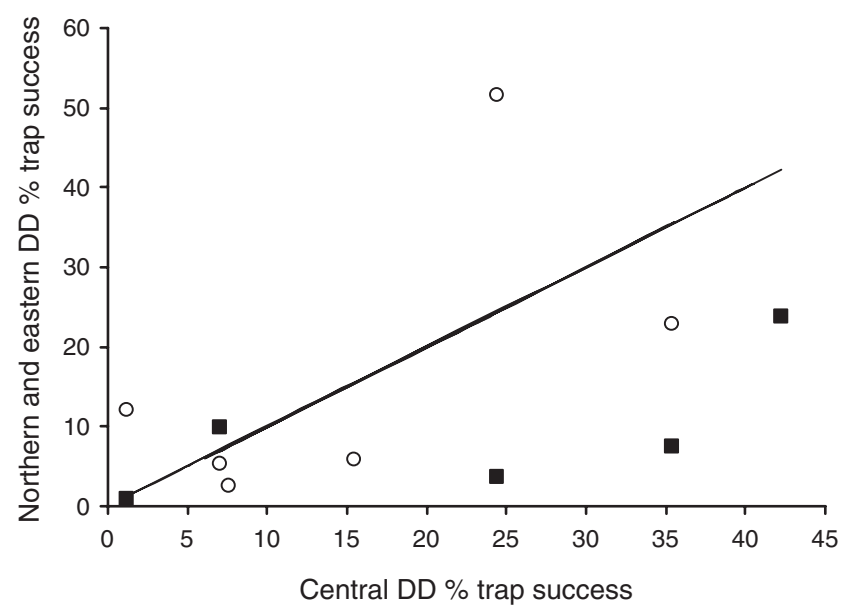

Fig. 3. Maximum monthly $\%$ trap success (unadjusted) recorded over autumn-winter (April-August) during 1998-2008 on the central Darling Downs (DD) transect, compared with corresponding years on the northern (open circles) and eastern (solid squares) Darling Downs transects. The straight line is $y=x$.

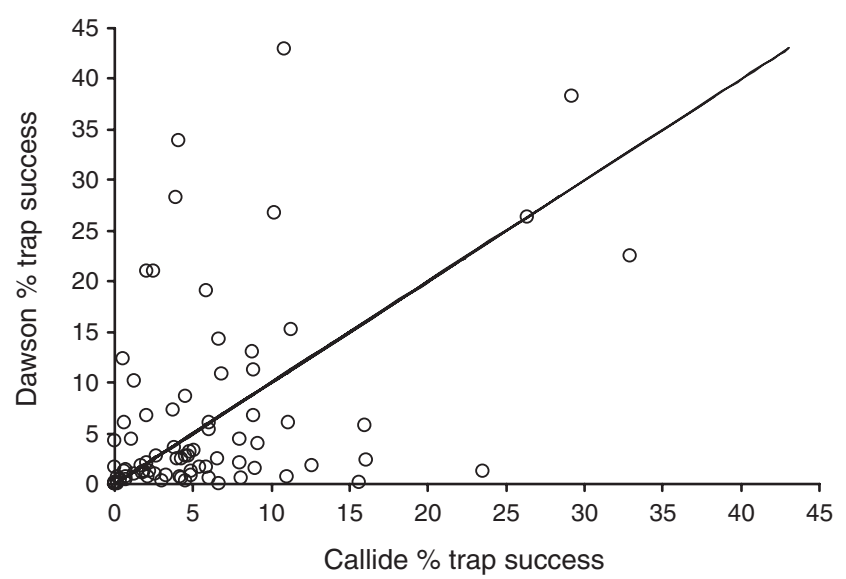

Fig. 4. Monthly \% trap success (unadjusted) recorded over 1998-2008 on the Dawson Valley transect, compared with corresponding months on the Callide Valley transect, both in central Queensland. The straight line is $y=x$. in the latter part of the time series, so true maxima may have been missed and the frequency of high densities is probably underestimated.

Autocorrelations and partial autocorrelations for adjusted trap success at increasing monthly lags on the central Darling Downs transect are shown in Fig. 5. The partial autocorrelations show the correlation remaining once the correlations with earlier months have been taken into account. Strong seasonal cycles are evident with a positive correlation at 2 years. Notably, there is no significant correlation at 12 months, although there is a significant negative partial correlation at 15 months. This does not support the long-term prediction of Cantrill (1992) using autumn density to predict autumn density in the following year.

A comparison of mixed models showed no significant trend in trap success over the time series $\left(\chi^{2}=0.90, P>0.3\right)$ for the central Darling Downs. This was supported by a non-significant regression of monthly mean adjusted trap success over time $\left(F_{1,30}=0.15, P>0.7\right)$.

\section{Darling Downs \\ Predicting mouse abundance}

For the central Darling Downs transect, the most parsimonious model (standardised coefficients are given here; unstandardised coefficients are given in Appendix 1) predicting autumn-winter mouse abundance and including September (spring) abundance $(n=27)$ as a potential explanatory variable was as follows:

$$
\begin{aligned}
& \log _{\mathrm{e}}(\text { autumn-winter adjusted trap success }) \\
& \quad=2.6404+0.5032 \text { (previous year's March-August rain) } \\
& \quad-0.6423(\text { September-December rain }) \\
& \quad+0.4465\left(\log _{\mathrm{e}}(\text { September adjusted trap success }+0.01)\right)
\end{aligned}
$$$$
\text { (Model 1). }
$$
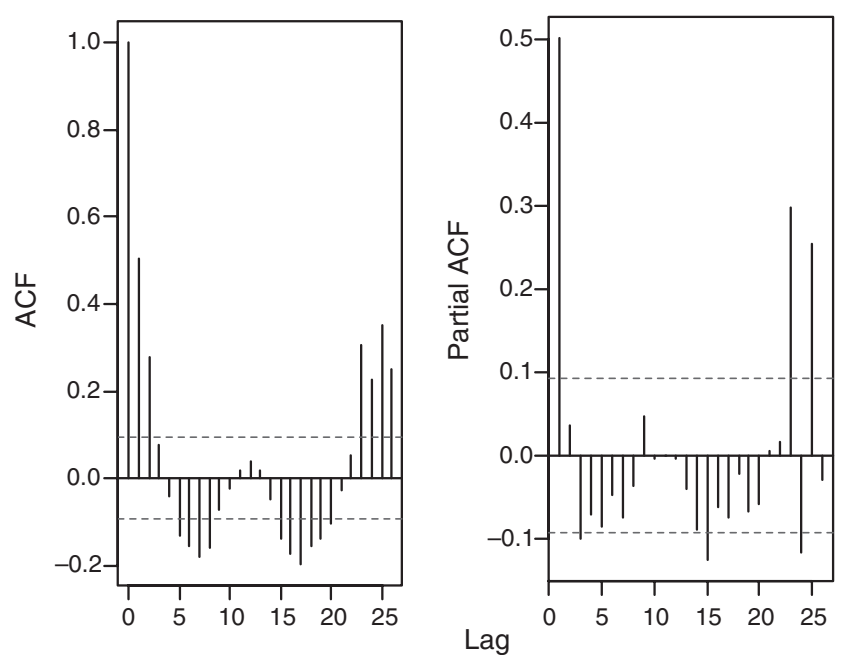

Fig. 5. Autocorrelations (ACF) and partial autocorrelations for adjusted trap success on the central Darling Downs transect (1974-2008) at increasing monthly lags. The dashed horizontal line indicates significance at $P=0.05$. 
This model had an $R^{2}$ of $57 \%$. If September abundance was removed, $R^{2}$ was reduced to $38 \%$. There was no support for curvilinear terms or interactions between the three variables. March-August (autumn-winter) rainfall is correlated with winter crop yield (Spearman's $\rho=0.67, P<0.001$ ), but the latter variable results in a model with poorer explanatory power when included in place of March-August rainfall. Using a dummy variable for flooding spring-summer rain instead of September-December rain does not improve the model $\left(R^{2}=49 \%\right)$. Using only September abundance produces a model explaining only $19 \%$ of the variance in contrast to the $56 \%$ recorded by Cantrill (1992) using a shorter time series.

The relationship between September and maximum autumn-winter abundances has considerable scatter (Fig. 6) and so, alone, September abundance is a poor indicator of future abundance. A September trap success of $>1 \%$, considered a threshold above which a plague is likely (Caughley 1998), does not guarantee high numbers over autumn-winter and would lead to numerous false plague warnings. There is also a false negative.

If September abundance is ignored, both the maximum autumn-winter trap success in the previous year and winter temperature are potential explanatory variables. Median minimum rather than lowest temperature over winter had the stronger correlation (Spearman's $\rho=0.356 \mathrm{cf} . \rho=0.204$ ) with maximum autumn-winter trap success, and so was used in the modelling. Again, there were no significant curvilinear terms following stepwise removal. Only two-way interactions were considered, leaving a final model with an almost identical $R^{2}$ as that of Model 1 with September abundance. This model did not include the maximum autumn-winter abundance of the previous year, which is weakly negatively correlated with the maximum abundance of the present year (Spearman's $\rho=-0.42, P<0.05)$, supporting the time-series analysis above.

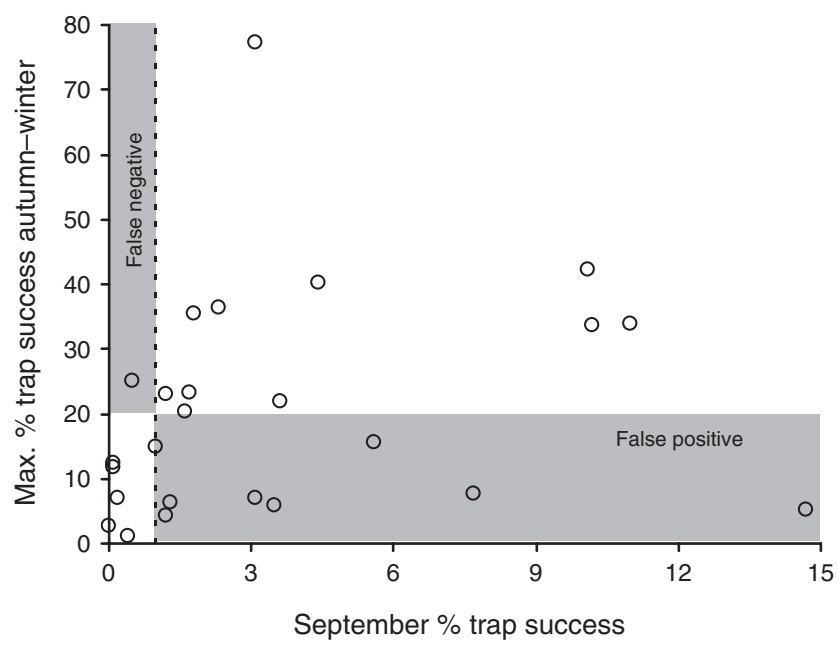

Fig. 6. Maximum \% trap success (unadjusted) in autumn-winter on the central Darling Downs transect as a function of September (spring) \% trap success (unadjusted) in the previous year. The dashed vertical line represents a September trap success of $1 \%$. September trap success $>1 \%$ was suggested by Caughley (1998) as an indicator of a likely plague the following autumn-winter. Shaded areas represent false predictions of high density ( $>20 \%$ trap success) or low density.
Excluding September abundance and the maximum autumn-winter abundance of the previous year allows the use of a larger dataset $(n=32)$. The same model was selected as with the smaller dataset and had the following standardised coefficients (unstandardised coefficients in Appendix):

$$
\begin{aligned}
& \log _{\mathrm{e}}(\text { autumn-winter adjusted trap success) } \\
& \quad=2.5301+0.4357 \text { (previous year's March-August rain) } \\
& -0.4329 \text { (September-December rain) }+0.3451 \\
& \text { (previous year's median monthly minimum } \\
& \text { June-August temperature) }+0.6265
\end{aligned}
$$$$
\text { (September-December rain) } \times(\text { previous year's median }
$$$$
\text { monthly minimum June-August temperature) (Model 2). }
$$

An indication of the fit of the two models is a plot of observed against predicted \% trap success over autumn-winter, which is shown in Fig. 7. Notably, both models fell short of predicting the magnitude of the 1995 plague (77\% trap success). Other anomalies were the high densities (>40\%) in 2001 and 2009 that were predicted to be of only moderate abundance (10-20\%), and a false negative in 1991.

\section{Cross-validation}

Models 1 and 2 provided 15 predictions of maximum \% trap success over autumn-winter for the northern and eastern Darling Downs transects (Fig. 8). Using 20\% trap success as a cut-off for high densities, for Model 1, there were two false negatives, seven correct negatives and one borderline result. For Model 2, there were three correct negatives, one false positive and one borderline result.

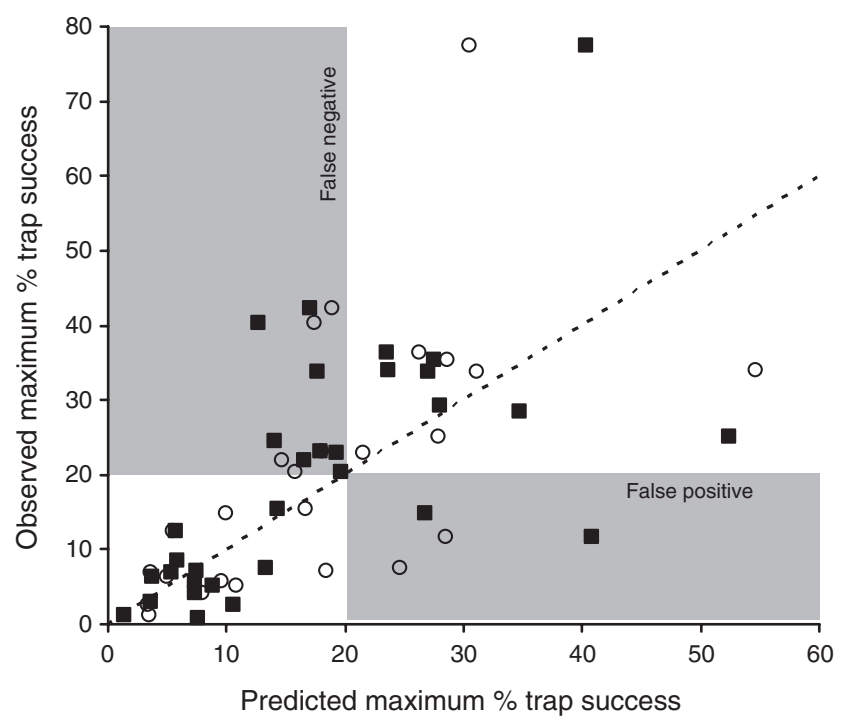

Fig. 7. Observed maximum $\%$ trap success (unadjusted) of mice over autumn-winter on the central Darling Downs transect plotted against predicted maximum \% trap success (back-transformed from adjusted to unadjusted) using Model 1 (open circles; including September (spring) abundance) and Model 2 (solid squares; using only rainfall and the minimum winter temperature from the previous year). The dashed line is $y=x$. See text for details. Shaded areas represent false predictions of high density ( $>20 \%$ trap success) or low density. 


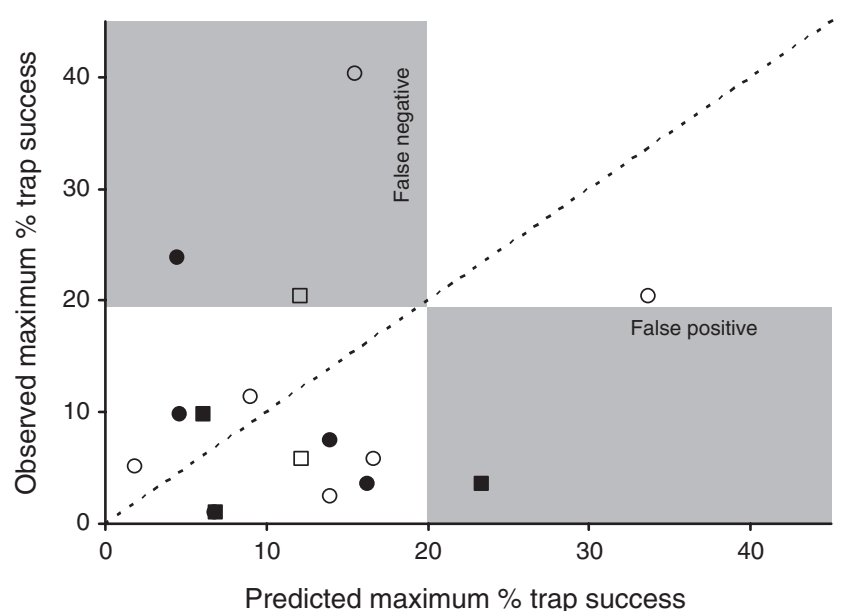

Fig. 8. Observed maximum \% trap success (unadjusted) of mice over autumn-winter on the northern (open symbols) and eastern (solid symbols) Darling Downs transects plotted against predicted maximum $\%$ trap success (back-transformed from adjusted to unadjusted) using Model 1 (circles; including September abundance) and Model 2 (squares; using only rainfall and the minimum winter temperature from the previous year). The dashed line is $y=x$. See text for details. Shaded areas represent false predictions of high density ( $>20 \%$ trap success) or low density.

\section{Determinants of rate of increase}

An analysis of covariance comparing the regression-based rates of increase $(r)$ over spring-autumn (September-May) among years found a significant time $\times$ year interaction $\left(F_{24,104}=1.98, P<0.01\right)$, indicating varying rates among years. The monthly exponential rates of increase over this period, on the basis of the regression slope, were between -0.23 and 0.74 . Plots indicated no obvious relationship between these rates and either spring-summer (September-February) rainfall, which had been found to delay the start of the increase phase, or autumn-winter (March-August) rainfall, which is an important influence in southern Australia. Further, monthly rates of increase following consecutive months of $>40-\mathrm{mm}$ rain over September-December $(r=0.26 \pm 0.06)$ were not significantly lower than those for drier years $(r=0.34 \pm 0.10)$.

For the central Darling Downs transect, using rates of increase calculated from two point estimates (i.e. average or maximum of seasonal values) of adjusted \% trap success provided a similar but generally larger dataset for analysis. The monthly exponential rates of increase from September to the maximum over April-August were between -0.14 and 0.70 . The most parsimonious regression model (standardised coefficients are given here; unstandardised coefficients are given in the Appendix) predicting this rate of increase contained the same set of explanatory variables as did the model predicting maximum abundance (Model 1), as follows:

$$
\begin{aligned}
& r \text { (September-maximum })=0.2702+0.0638 \\
& \quad(\text { previous year's March-August rain })-0.0800 \\
& \quad(\text { September-December rain })-0.1566 \\
& \quad\left(\log _{\mathrm{e}}(\text { September adjusted trap success }+0.01)(\text { Model } 3) .\right.
\end{aligned}
$$

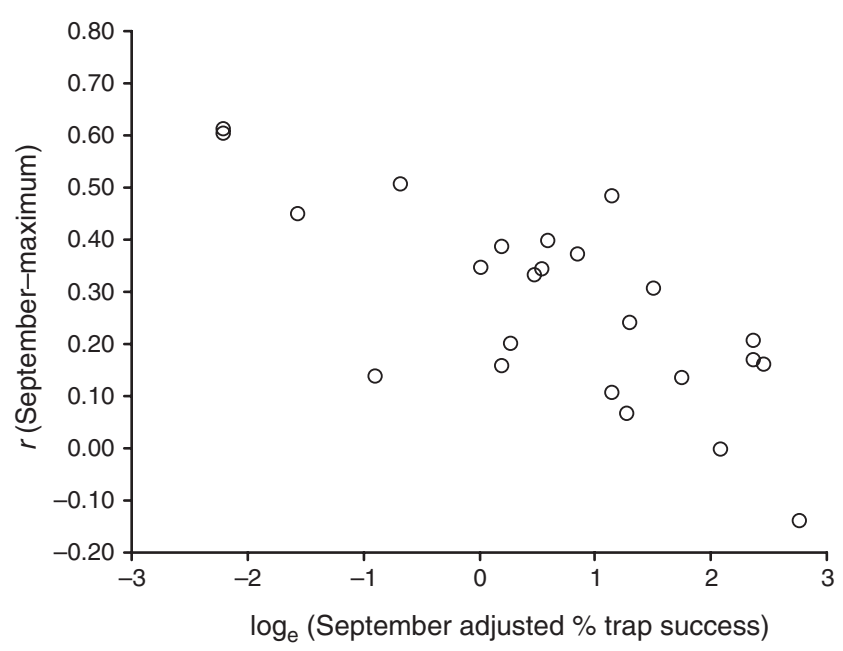

Fig. 9. Relationship between the observed monthly exponential rate of increase of mice (between September (spring) and the maximum abundance over autumn-winter) and logged September adjusted \% trap success on the central Darling Downs transect. See text for details.

This model had an $R^{2}$ of $80 \%$. There was no support for curvilinear terms or interactions between the three variables. Again, using a dummy variable for flooding, spring-summer rain instead of September-December rain did not improve the model $\left(R^{2}=76 \%\right)$. With only September abundance, $R^{2}$ is reduced to $62 \%$ (Fig. 9). Either alone or together, the two rainfall terms did not have significant relationships with $r$ (September-maximum). Other rainfall periods (i.e. AprilOctober, July-December) and winter crop yield were similarly unrelated to $r$ (September-maximum). This precluded developing a numerical-response model for mice (e.g. Brown and Singleton 1999; Pech et al. 1999) from these data.

Given September abundance, Model 3 can be used for prediction of maximum abundance over April-August. When the explanatory variables were held at their mean values, mouse abundance increased at a monthly rate of 0.27 . Using this rate in an example, average September abundance over the study period was $3.6 \%$ unadjusted trap success, which would, on average, increase to $27.2 \%$ unadjusted trap success in May. Not surprisingly, a comparison of predicted with observed maximum abundance for the central Darling Downs using Model 3 and September abundance produced plots almost identical to those in Figs 7 and 8. Cross-validation of Model 3 with data from the northern and eastern Darling Downs transects produced a plot similar to that in Fig. 8, with one false and one borderline false negative, and three correct negatives.

Outside the overwinter decline, maximum monthly exponential rates of increase between seasons ranged from 0.48 over spring-summer to 1.29 over summer-autumn. Best models (with standardised coefficients) for predicting monthly exponential rates of increase between seasons were the following:

$$
r \text { (September-summer) - no significant explanatory }
$$
variables; 


$$
\begin{aligned}
& r(\text { summer-autumn })=0.4715-0.3504 \\
& \quad\left(\log _{\mathrm{e}}(\text { summer adjusted trap success }+0.01)\right), \\
& \quad R^{2}=57 \%(\text { Model } 4)
\end{aligned}
$$

$$
\begin{aligned}
& r(\text { autumn-winter })=0.1485-0.5876 \\
& \left(\log _{\mathrm{e}}(\text { autumn adjusted trap success }+0.01)\right) \\
& +0.4576\left(\log _{\mathrm{e}}(\text { autumn adjusted trap success }+0.01)\right)^{2} \\
& +0.1194(\text { summer crop yield }), R^{2}=53 \%(\text { Model } 5) ; \text { and } \\
& r(\text { maximum-September })=-0.5247-0.4239 \\
& \left(\log _{\mathrm{e}}(\text { maximum adjusted trap success })\right), \\
& R^{2}=54 \%(\text { Model } 6) .
\end{aligned}
$$

In all cases, neither rainfall nor crop variables (i.e. proxies for food supply) alone were significantly related to $r$.

\section{Central Queensland}

In the Dawson Valley, mouse numbers increased on average over spring-summer (mean monthly $r=0.23 \pm 0.22$ ), declined over summer-autumn (mean monthly $r=-0.36 \pm 0.15$ ), increased over autumn-winter (mean monthly $r=0.13 \pm 0.18$ ) and declined over winter-spring (mean monthly $r=-0.27 \pm 0.27$ ). In the Callide Valley, the pattern is similar, with mouse numbers declining on average over springsummer (mean monthly $r=-0.05 \pm 0.19$ ), declining over summer-autumn (mean monthly $r=-0.22 \pm 0.22$ ), increasing over autumn-winter (mean monthly $r=0.52 \pm 0.25$ ) and declining over winter-spring (mean monthly $r=-0.24 \pm 0.25$ ). Declines in both cases over summer-autumn contrasted strongly with mouse rate of increase for the corresponding period on the Darling Downs.

Correlates of these rates of increase are shown in Tables 1 and 2, and the relationships differed among the valleys, as Fig. 4 would suggest. In the Dawson Valley, 6-monthly rainfall with a short lag was positively correlated with rate of increase over summer-autumn and winter-spring, which was consistent with the results from the central Darling Downs above. However, the rainfall from the previous winter had a negative relationship with $r$ over autumn-winter. In contrast, there were no significant relationships between rainfall and the rate of increase in the Callide Valley. As expected from results on the central Darling Downs, initial mouse abundance was negatively correlated with the (tendency for an) overwinter decline in the Callide Valley, but not the Dawson Valley. High autumn abundance on both transects tended to dampen the regular increase over autumn-winter.

For both transects, there were correlations between rainfall and seasonal trap success (Tables 1, 2). In many cases, it was autumn-winter rainfall that appeared influential, as on the Darling Downs. The stronger correlations suggested that it is worthwhile to consider three regression models (see below) to predict seasonal mouse abundance (unstandardised coefficients), although the prediction for the Callide Valley provides little advance warning.
Table 1. Strongest, significant $(P<0.05)$ Spearman's rank correlations between exponential rates of increase $(r)$ between seasons and either 6-monthly rainfall or starting mouse abundance (adjusted \% trap success), and between seasonal, adjusted \% trap success and 6-monthly rainfall in the Dawson Valley, central Queensland n.s., not significant. See text for details

\begin{tabular}{lccc}
\hline Response variable & Correlate & Spearman's $\rho$ & $P$ \\
\hline$r$ vs rainfall & & & \\
$r$ (spring-summer) & & & n.s. \\
$r$ (summer-autumn) & Rain (September-February) & 0.75 & 0.02 \\
$r$ (autumn-winter) & Rain (May-October) & -0.87 & 0.005 \\
$r$ (winter-spring) & Rain (March-August) & 0.70 & 0.03 \\
$r$ vs mouse abundance & & & \\
$r$ (spring-summer) & & & n.s. \\
$r$ (summer-autumn) & & & n.s. \\
$r$ (autumn-winter) & Autumn trap success & -0.78 & 0.02 \\
$r$ (winter-spring) & & & n.s. \\
Seasonal trap success vs rainfall & & \\
Spring trap success & Rain (January-June) & 0.72 & 0.01 \\
Summer trap success & Rain (January-June) & 0.80 & 0.005 \\
Autumn trap success & Rain (March-August) & 0.84 & 0.001 \\
Winter trap success & & & n.s. \\
\hline
\end{tabular}

Table 2. Strongest, significant $(P<0.05)$ Spearman's rank correlations between exponential rates of increase $(r)$ between seasons and either 6-monthly rainfall or starting mouse abundance (adjusted \% trap success), and between seasonal, adjusted \% trap success and 6-monthly rainfall in the Callide Valley, central Queensland n.s., not significant. See text for details

\begin{tabular}{lccc}
\hline Response variable & \multicolumn{1}{c}{ Correlate } & Spearman's $\rho$ & $P$ \\
\hline$r$ vs rainfall & & \\
$r$ (spring-summer) & & n.s. \\
$r$ (summer-autumn) & & n.s. \\
$r$ (autumn-winter) & & n.s. \\
$r$ (winter-spring) & & n.s. \\
$r$ vs mouse abundance & & & \\
$r$ (spring-summer) & & & n.s. \\
$r$ (summer-autumn) & Autumn trap success & -0.88 & 0.002 \\
$r$ (autumn-winter) & Winter trap success & -0.66 & 0.04 \\
$r$ (winter-spring) & & & \\
& & & \\
Seasonal trap success vs rainfall & & 0.76 & 0.009 \\
Spring trap success & Rain (March-August) & 0.03 \\
Summer trap success & Rain (March-August) & 0.75 & 0.03 \\
Autumn trap success & Rain (March-August) & 0.58 & 0.05 \\
Winter trap success & Rain (July-December) & 0.68 & 0.03 \\
\hline
\end{tabular}

\section{Dawson Valley}

$$
\begin{aligned}
& \log _{\mathrm{e}}(\text { summer adjusted trap success }+0.1) \\
& \quad=-3.0693+0.0142 \text { (January-June rain), } \\
& R^{2}=60 \%(\text { Model } 7) \text { and } \\
& \left.\log _{\mathrm{e}} \text { (autumn adjusted trap success }+0.1\right) \\
& \quad=-2.0184+0.0140 \text { (March-August rain), } \\
& R^{2}=53 \%(\text { Model } 8) .
\end{aligned}
$$




\section{Callide Valley}

$$
\begin{aligned}
& \log _{\mathrm{e}}(\text { spring adjusted trap success }+0.1) \\
& \quad=-1.4875+0.0146 \text { (March-August rain), } \\
& \left.R^{2}=51 \% \text { (Model } 9\right)
\end{aligned}
$$

Regression models predicting winter mouse abundance from summer rainfall and summer mouse abundance, as broadly suggested by Scanlan and Farrell (2005), resulted in a nonsignificant model for the Callide Valley, and a good fit $\left(R^{2}=86 \%\right)$ for the Dawson Valley. The latter result is misleading because rainfall was barely significant $(P \cong 0.05)$ and summer mouse abundance had the strongest influence. The latter relationship is not surprising because autocorrelation is expected in these data, although perhaps not at a 6-month lag (see Fig. 5). The regression is also greatly influenced by a single point of high abundance in both seasons in 2004.

\section{Discussion}

A 32-year time series of mouse abundance showed a plague frequency of 1 in 4 years, but damaging mouse densities occurred on average every second year in the central Darling Downs. Such a high risk of mouse impact warrants an early warning system. This could be a predictive model giving a warning some months in advance of high mouse numbers or, alternatively, regular direct monitoring could provide the warning and with much greater certainty. Quite clearly, however, the central Darling Downs transect did not consistently provide an early warning even for nearby transects and so the relative abundance on that transect should not be extrapolated to a broader area. This is consistent with Caughley's (2001) argument that monitoring needs to be undertaken at the scale of an individual farm. This was based on a 1997 survey of grain growers across the Darling Downs who reported different timing, severity and frequency of mouse plagues over the previous 5 years (Donkin and Caughley 1998). Local monitoring in September can indicate the potential for a plague as part of a model (e.g. Model 1), rather than a threshold such as $1 \%$ trap success.

The model-based warning system presented here should be useful, providing a warning several months ahead of a plague, but there is uncertainty in the prediction. Figs 7 and 8 showed that there will be false negatives and positives. Although this uncertainty alone would make a crop farmer reluctant to bait, it is likely that they would delay baiting anyway. Mouse populations may well decline, before the crop has matured and is at greatest risk of damage, and so the warning could most realistically trigger closer monitoring of mouse abundance. A warning of a plague would give bait suppliers time to build up sufficient stock of bait and give government agencies and agribusinesses time to plan the necessary logistical and technical support for grain growers.

Autumn-winter rainfall, overlooked as a predictor of the mouse abundance in the following year in previous analyses of these data, proved to be important, as it is in models predicting mouse abundance in southern Australia. In central Queensland too, winter rainfall is often the best correlate of seasonal mouse abundance, but the correlation is often weak. In the Dawson
Valley, autumn-winter rainfall provides a simple indicator of mouse abundance in the following summer and autumn.

One limitation to these results is that the time series was incomplete, particularly for the past 10 years. This meant that the month and size of the yearly maxima could not be accurately identified in several years and rates of increase between seasons were approximate because trapping was conducted only in 1 month of many seasons. This shortcoming is at least partly overcome by the length of the time series, whereby bias in one year should be offset by counter bias in other years. Nevertheless, this will add noise to the data and uncertainty to the predictions. The data also came from only a single-night trapping at each site along the transects. This is considered unreliable because of the night-to-night variation in trap success for house mice observed in other studies (Davis et al. 2003; Kaboodvandpour et al. 2010). Although this could be a problem at a local scale of a single farm (i.e. $<100 \mathrm{~km}^{2}$ ), the transects in the present study provided abundance estimates at a regional scale of numerous farms. The imprecision seen at a site with 20-25 traps will therefore have been dampened across transects comprising from 200 to almost 1000 traps in the present study.

Estimates of maximum monthly rate of increase $\left(r_{\mathrm{m}}\right)$ ranged from 0.7 to 1.3 , being lowest when calculated between September and the annual maximum abundance estimates and highest when the calculation was restricted to a period when mice were consistently increasing between summer and the annual maximum. These estimates fell around the $r_{\mathrm{m}}$ of 1.2 recorded directly in cropping systems in southern Australia (Brown and Singleton 1999), or 0.87 based on vital rates including a fortnightly survival rate on the Darling Downs of 0.95 and a recruitment rate of seven young per pregnancy (Krebs et al. 1994). Model 3 predicts that mice will increase on average at a monthly exponential rate of 0.27 from September, being well short of the maximum rate. Several factors ameliorate this potential rate of increase. Identified here and by Cantrill (1992) is a delay in the start of the increase phase and the negative impact of flooding summer rain (Models 1-3). Other factors affecting the realised rate of increase were clearly not captured by the simple models here.

Surprisingly, rate of increase was only weakly related to either rainfall or crop yield, the two surrogates of food supply. Initial mouse abundance was the stronger influence, but this evidence for density dependence is unsatisfactory. Although there is a strong negative relationship between $r$ (September-maximum) and September abundance (Model 3; Fig. 9), the latter is included in both response and explanatory variables, violating an assumption of linear regression and potentially overestimating the strength of density dependence (Burgman et al. 1993; McCarthy 1996). Further, uncertainty in abundance estimates leads to anomalous fluctuations in a time series leading to an overestimation of the strength of density dependence through regression analyses (McCarthy 1996; Pople et al. 2010). Despite these concerns, the relationship here is unlikely to be an artefact of observation error or a statistical anomaly, and so warrants discussion. The relationship is at least partly an artefact of a continuation in the regular winter decline in the population. In 16 of 20 years with data, the population declined from September to October or November. The low point of the 
population cycle, calculated as the mean or median of $\%$ trap success for each month across years over the study period, was in October and November. December also had a lower median $\%$ trap success than did September. This was observed by Cantrill (1992) who argued that identification of the start of the increase phase was important for predicting maximum abundance over autumn-winter. This emphasises the point that September abundance alone is a poor predictor of a plague.

Nevertheless, there were strong negative relationships between density and the other rates of increase between seasons from summer onwards on the Darling Downs and in central Queensland. For the overwinter decline, the relationship was expected (Cantrill 1992; Pech et al. 2003), and for $r$ over autumn-winter, the population was often already declining. However, during the breeding season, rate of increase was generally monotonic and was expected to be largely independent of the starting density (Pech et al. 2003).

Finally, it is worth noting that increasing the length of a time series has not led to more accurate predictions of, in this case, mouse abundance. It has allowed reappraisal of previous modelling, correcting some misinterpretations such as the rate of increase during the breeding season being constant from year to year. Autumn-winter rainfall was also identified as an important positive influence on mouse abundance. The regular pattern of seasonal cycles observed in mouse populations in Queensland grain crops suggests that the maximum abundance there should be more predictable than the maximum abundance in the irregular dynamics observed in southern Australian grain crops; however, that is not the case. The inability to predict accurately appears to be a problem in measuring the major factors (e.g. invertebrate and plant-food supply, predators and disease) influencing the rate of increase of mouse populations (Krebs et al. 2004). It also highlights the importance of monitoring mouse numbers, at the scale of a farm, both to support a predictive model and to directly indicate the need to control mouse abundance.

\section{Acknowledgements}

The data presented here have been collected by numerous people, including the late John Wilson, Steve Cantrill, Christine Donkin, Judy Caughley, John Conroy, Craig Hunter and Kevin Strong. Their efforts in building what has now become a valuable long-term dataset are greatly appreciated. We also thank Pat Abbott who collated data on grain yield in Queensland. All trapping was undertaken with animal ethics permits (latest PAEC number 030605) from the now Queensland Department of Agriculture, Fisheries and Forestry. Wilmot Senaratne kindly prepared Fig. 1. This work was supported by funding from the Grains Research and Development Corporation. We are grateful to two anonymous reviewers whose comments improved the manuscript.

\section{References}

Brown, P. R., and Singleton, G. R. (1999). Rate of increase as a function of rainfall for house mouse Mus domesticus populations in a cereal-growing region in southern Australia. Journal of Applied Ecology 36, 484-493. doi:10.1046/j.1365-2664.1999.00422.x

Brown, P. R., Davies, M. J., Singleton, G. R., and Croft, J. D. (2004). Can farm-management practices reduce the impact of house mouse populations on crops in an irrigated farming system? Wildlife Research 31, 597-604. doi:10.1071/WR03063
Burgman, M. A., Ferson, S., and Akcakaya, H. R. (1993). 'Risk Assessment in Conservation Biology.' (Chapman and Hall: London.)

Cantrill, S. (1992). The population dynamics of the house mouse (Mus domesticus) in a dual crop agricultural ecosystem. Ph.D. Thesis, Queensland University of Technology, Brisbane.

Caughley, G. (1977). 'Analysis of Vertebrate Populations.' (Wiley and Sons: London.)

Caughley, J. A. (1998). 'House Mouse (Mus domesticus) in Queensland.' (Department of Natural Resources and Mines: Brisbane.)

Caughley, J. (2001). Optimisation of zinc phosphide baiting to control mice. GRDC project no. DNR 8. Final report to the Grains Research and Development Corporation, Canberra.

Crawley, M. J. (2007). 'The R Book.' (Wiley and Sons: Chichester, UK.)

Davis, S. A., Akison, L. K., Farroway, L. N., Singleton, G. R., and Leslie, K. E. (2003). Abundance estimators and truth: accounting for individual heterogeneity in wild house mice. The Journal of Wildlife Management 67, 634-645. doi:10.2307/3802720

Davis, S. A., Leirs, H., Pech, R., Zhang, Z., and Stenseth, N. C. (2004). On the economic benefit of predicting rodent outbreaks in agricultural systems Crop Protection 23, 305-314. doi:10.1016/j.cropro.2003.09.002

Donkin, C., and Caughley, J. (1998). Are mouse plagues increasing in frequency in Queensland? In '11th Australian Vertebrate Pest Conference', Bunbury, WA. pp. 241-246. 3-8 May 1998.

Kaboodvandpour, S., and Leung, L. K. P. (2012). Modelling density thresholds for managing mouse damage to maturing wheat. Crop Protection 42, 134-140. doi:10.1016/j.cropro.2012.07.013

Kaboodvandpour, S., Free, C., and Leung, L. K. (2010). Comparison of population estimators and indices for monitoring house mice in sorghum crops. Integrative Zoology 5, 53-62. doi:10.1111/j.1749-4877. 2010.00189.x

Kenney, A., Krebs, C., Davis, S., Pech, R., Mutze, G., and Singleton, G. (2003). Predicting house mice outbreaks in the wheat growing areas of southeastern Australia? In 'Rats, Mice and People: Rodent Biology and Management'. (Eds G. Singleton, L. Hinds, C. Krebs and D. Spratt.) pp. 325-328. (ACIAR: Canberra.)

Krebs, C., Singleton, G., and Kenney, A. (1994). Six reasons why feral house mouse populations might have low recapture rates. Wildlife Research 21, 559-567. doi:10.1071/WR9940559

Krebs, C. J., Kenney, A. J., Singleton, G. R., Mutze, G., Pech, R. P., Brown, P. R., and Davis, S. A. (2004). Can outbreaks of house mice in southeastern Australia be predicted by weather models? Wildlife Research 31, 465-474. doi:10.1071/WR03131

McCarthy, M. A. (1996). Red kangaroo (Macropus rufus) dynamics: effects of rainfall, density dependence, harvesting and environmental stochasticity. Journal of Applied Ecology 33, 45-53. doi:10.2307/240 5014

Mutze, G., Veitch, L., and Miller, R. (1990). Mouse plagues in South Australian cereal-growing areas. II. An empirical model for prediction of plagues. Wildlife Research 17, 313-324. doi:10.1071/WR9900313

Neter, J., Kutner, M. H., Nachtsheim, C. J., and Wasserman, W. (1996). 'Applied Linear Statistical Models.' 4th edn. (Irwin: Burr Ridge, IL.)

Pech, R. P., Hood, G. M., Singleton, G. R., Salmon, E., Forrester, R. I., and Brown, P. R. (1999). Models for predicting plagues of house mice (Mus domesticus) in Australia. In 'Ecologically-based Management of Rodent Pests'. (Eds G. R. Singleton, L. A. Hinds, H. Leirs and Z. Zhang.) pp. 81-112. (Australian Centre for International Agricultural Research: Canberra.)

Pech, R. P., Davis, S. A., and Singleton, G. R. (2003). Outbreaks of rodents in agricultural systems: pest control problems or symptoms of dysfunctional ecosystems? In 'Rats, Mice and People: Rodent Biology and Management'. (Eds G. Singleton, L. Hinds, C. Krebs and D. Spratt.) pp. 311-315. (ACIAR: Canberra.)

Pople, A., Grigg, G., Phinn, S., Menke, N., McAlpine, C., and Possingham, H. (2010). Reassessing spatial and temporal dynamics of kangaroo 
populations. In 'Macropods: the Biology of Kangaroos, Wallabies and Rat-kangaroos'. (Eds G. Coulson and M. D. B. Eldridge.) pp. 197-210. (CSIRO Publishing: Melbourne.)

R Development Core Team (2010). 'R: a Language and Environment for Statistical Computing.' 2.11.0 edn. (R Foundation for Statistical Computing: Vienna.)

Scanlan, J. C., and Farrell, J. (2005). A preliminary mouse abundance prediction model for the central Queensland grain producing region. In '13th Australian Vertebrate Pest Conference', Wellington, New Zealand. pp. 44-47.
Singleton, G. R., and Brown, P. R. (1999). Management of mouse plagues in Australia: integration of population ecology, bio-control and best farm practice. In 'Advances in Vertebrate Pest Management.' (Eds DP Cowan and CJ Feare.) pp. 189-203. (Filander-Verlag: Berlin.)

Singleton, G. R., Brown, P. R., Pech, R. P., Jacob, J., Mutze, G. J., and Krebs, C. J. (2005). One hundred years of eruptions of house mice in Australiaa natural biological curio. Biological Journal of the Linnean Society. Linnean Society of London 84, 617-627. doi:10.1111/j.1095-8312.2005. 00458.x 
Appendix 1. Unstandardised coefficients for regression models predicting mouse abundance and monthly exponential rate of increase

The models are the same as the equivalent model in the main text with standardised coefficients

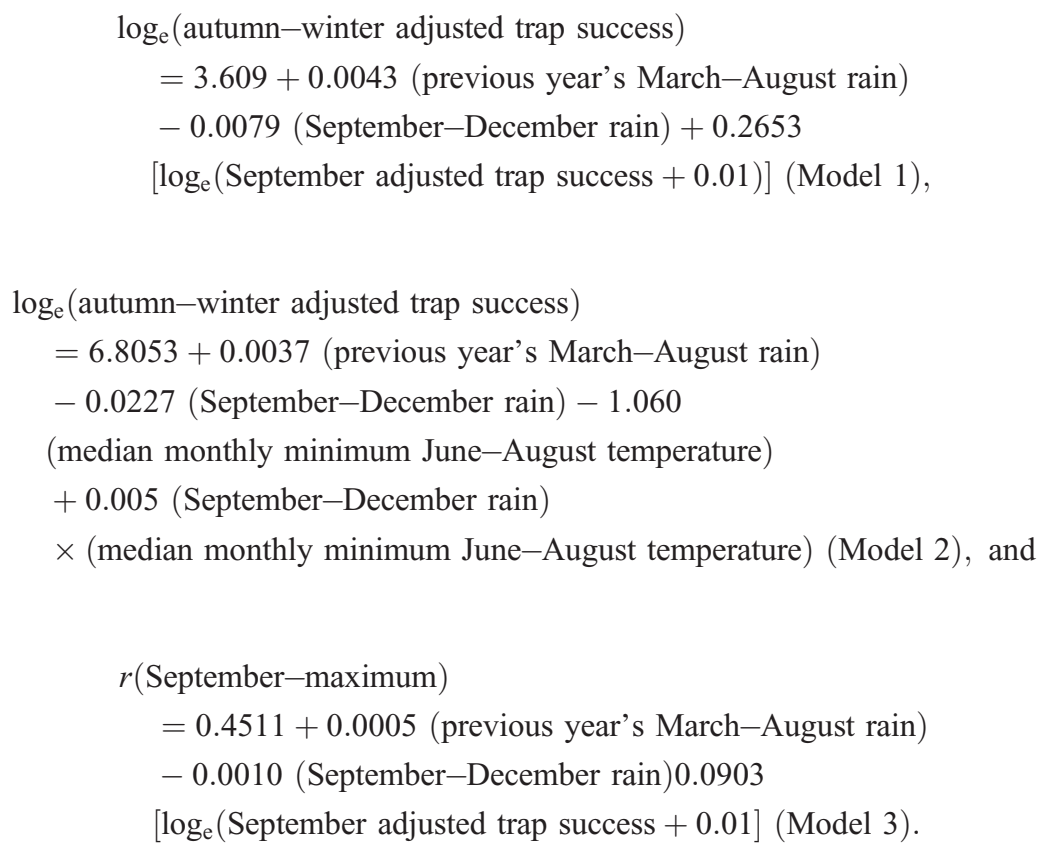

